УДК: $316.776 .3: 378.4$

$10.17213 / 2075-2067-2020-5-127-134$

\title{
ДИАЛОГ В УПРАВЛЕНИИ УНИВЕРСИТЕТОМ В ИЗМЕНЯЮЩЕЙСЯ СОЦИАЛЬНОЙ РЕАЛЬНОСТИ: СОЦИОСТРУКТУРНЫЕ И КОММУНИКАТИВНЫЕ АСПЕКТЫ
}

\author{
(C) 2020 г. Л. И. Щербакова
}

\section{Южнн-Российский государственный политехнический университет (НПИ) имени М. И. Платова, г. Новочеркасск, Россия}

Целью исследования является конщептуализащия социального диалога в системе уnравления современным университетом как специифической разновидности социальной коммуникации, механизма социильной консолидации и согласования интересов и действий основных субъектов образовательного процесса в условиях новой сочиильной реальности.

Методологическая база исследования внутриуниверситетских соичоструктурных и коммуникативных взаимодействий опирается на идеи П. Штомпки о соииальных изменениях как прочессе, влияющем на изменение структуры системы, то есть четырех сетей связей между элементами: взаимодействиями (интеракциями), интересами, нормами и идеями [11]. Социальный диалог в образовательной системе рассмотрен как равноправное, свободное и продуктивное коммуникативное взаимодействие, имеющее своей иелью сплоченность и солидаризацию всех субъектов образования на принципах партнерства, уважения, толерантности. Изменяющаяся социальная реальность как внешняя среда функиионирования социального института высшего образования [8] рассмотрена в контексте научных обобщений российских ученых, обращающих внимание на то, что современная социальная реальность является результатом объективизации субъективной деятельности человека, она развивается по собственным объективным законам и оказывает влияние на человека и природу в целом.

Внутренняя университетская среда охарактеризована как особое сочиальное пространство, в котором каждый субъект образования описан на основе системы стратификационных координат, определяющих его социальное положение, главными из которых являются его властный, профессиональный и экономический статусы, уровень образования, семейное положение, национальность, происхождение и т.д. [9].

Результаты исследования заключаются в следующем: идентифицированы основные субъекты социального диалога университета, описаны тенденции трансформаций их интересов в изменяющцейся сочиальной реальности. Сочиальный диалог как технология общения и механизм выявления социальных проблем и противоречий в социальном пространстве университета охарактеризован как ресурс повышения эффективности управления, социальной консолидации, стабильности и солидарности в коллективе.

Дальнейшее исследование предполагает уточнение социокультурных регуляторов формирования мотивов, интересов субъектов образования в условиях трансформачии института выстего образования и поиск форм сочиального диалога в реальной среде и онлайн-формате для повышения эффективности управления университетом в новой социальной реальности.

Ключевые слова: сочиальный диалог; сочиальное пространство университета; стратификационные различия: субъекты образования; управленческие технологии. 


\title{
DIALOGUE IN UNIVERSITY MANAGEMENT IN A CHANGING SOCIAL REALITY: SOCIOSTRUCTURAL AND COMMUNICATIVE ASPECTS
}

\author{
(C) 2020 L. I. Shcherbakova
}

\section{Platov South Russian State Polytechnic University (NPI), Novocherkassk, Russia}

The aim of the research is to conceptualize social dialogue in the management system of a modern University as a specific type of social communication, a mechanism for social consolidation and coordination of interests and actions of the main subjects of the educational process in the new social reality.

The methodological basis for the study of intra-University sociostructural and communicative interactions is based on the ideas of P. Shtompka about social changes as a process that affects changes in the structure of the system, that is, four networks of connections between elements: interactions (interactions), interests, norms and ideas [11]. Social dialogue in the educational system is considered as an equal, free and productive communicative interaction, which aims to unite and solidify all subjects of education on the principles of partnership, respect, and tolerance. Changing social reality as an external environment for the functioning of a social institution of higher education [8] is considered in the context of scientific generalizations of Russian scientists, who draw attention to the fact that modern social reality is the result of objectification of subjective human activity, it develops according to its own objective laws and has an impact on man and nature as a whole. The internal University environment is characterized as a special social space in which each subject of education is described on the basis of a system of stratification coordinates that determine its social status, the main of which are its power, professional and economic status, level of education, marital status, nationality, origin, etc. [9].

The results of the research are as follows: the main subjects of the University's social dialogue are identified, and the trends of changes in their interests in the changing social reality are described. Social dialogue as a communication technology and a mechanism for identifying social problems and contradictions in the social space of the University is described as a resource for improving the effectiveness of management, social consolidation, stability and solidarity in the team.

Further research involves clarifying the socio-cultural regulators of the formation of motives and interests of educational subjects in the context of the transformation of the Institute of higher education and searching for forms of social dialogue in the real environment and online format to improve the effectiveness of University management in the new social reality.

Key words: social dialogue; social space of the University; stratification differences: subjects of education; manage.

Введение. В настоящее время в управлении университетом обозначилась насущная потребность в социальном диалоге как технологии и механизме выявления социальных проблем, согласования позиций социальных субъектов образования с иногда несовпадающими или противоречивыми интересами, а также налаживания между ними конструктивного коммуникативного взаимодействия, основанного на принципах социального и личного партнерства, равенства и доверия с целью локализации и разрешения возникающих противоречий и рисков. Внешней средой функционирования университетов является ускоренно развивающаяся социальная реальность, затрагивающая сферы научного и технологического знания, образования, производства и потребления, систему организации 
труда и досуга, социальную структуру общества. Как подчеркивают специалисты института социально-политических исследований Федерального научно-исследовательского социологического центра РАН, переход к новой стадии развития общества обострил два базовых противоречия, присущих динамике человеческой цивилизации: «культурное отставание», проявляющееся в рассогласовании ускоренного технологического развития и более медленной трансформации культурных паттернов и морально-нравственного состояния общества, и «управленческое отставание», связанное с усиливающимся влиянием знания на процессы управления в условиях усложнения социальной реальности. Кроме этого, они обращают внимание на то, что информационное и инновационное пространство как существенное качество этой реальности во многом определяют социальные и социокультурные процессы. В этих условиях изменение содержания и организации образовательного процесса (асинхронное обучение, традиционные и дистанционные технологии) сопровождается турбулентностью во мнениях и поведении субъектов образования, обнаруживает как негативные, так и позитивные тенденции, связанные с тем, что «в результате применения инноваций в технологиях образования повышается его качество, оно становится гибким, доступным, и, кроме того, формируются свойства специалиста, которые недостижимы при использовании традиционных подходов к обучению» [7, с. 273]. Уместно подчеркнуть тот факт, что детерминированные повышением роли знаний и образования расширяются возможности социального действия индивидов и дифференциаций стратегий их поведения, причем эти процессы всегда происходят быстрее на индивидуальном уровне и уровне социальных групп, в нашем случае - на уровне субъектов образования и в университетских сообществах [1].

Не ставится под сомнение тот факт, что наука и образование остаются системообразующими социальными институтами, посредством и благодаря которым представляется возможным создание, реализация, анализ и прогнозирование развития новой социальной реальности. Институт образования в социальных трансформациях остается своеобразным базисом, «зеркалом» общества, пос- кольку именно ему принадлежит функция, посредством которой происходит трансфер знания, селекция и «производство» человеческих ресурсов, «готовых» к высокопроизводительной деятельности.

Социальный диалог в управлении университетом: коммуникативное измерение. Уточним, что подразумевается под диалогом в социальном знании. Как считает ростовский ученый-философ В.И. Курбатов, социальный диалог есть социальная коммуникация, которая представляет собой коммуникативное взаимодействие, связанное с обменом социальными смыслами в социальном времени и социальном пространстве [6]. Учитывая, что университетская система представляет собой пространство регулируемых формальных и неформальных коммуникаций, социальный диалог может рассматриваться в качестве механизма функционирования и изменения этих коммуникаций. Роль социального диалога как фактора и технологии динамичной сбалансированности интересов субъектов образования заключается в равноправном участии всех участников диалога, в ориентации на конструктивное развитие данного социального процесса с опорой на нормативно-правовые, доверительные и морально-нравственные основания, на отрицание возможности использования теневых стратегий осуществления диалога.

Стоит обратить внимание на то, что под диалогом понимается вид коммуникаций, который предполагает как минимум двух субъектов. Существенный признак диалога — процессуальная структура, присутствие смены говорящего, попеременное владение словом, попеременное высказывание, обмен информацией, мыслями, смыслами, обоснование и отстаивание своей позиции, выраженной словами [10]. Именно на эти отличительные характеристики обращает внимание Ю.Н. Емельянов, подчеркивающий, что диалог — это разговор равных, отражающий уровень их коммуникативной компетентности, рассматриваемой как развивающийся целостный жизненный опыт, осознанный и этически упорядоченный индивидом [2]. Правила диалогического взаимоотношения субъектов образования - ответственность, заинтересованность, непредвзятость, открытость. 
Социальный диалог в управлении университетом: социоструктурный аспект. Социоструктурное измерение социального диалога среди субъектов образования в университете может быть охарактеризовано с учетом неоинституциональных подходов Д. Норта, наиболее существенным из которых в контексте изучаемой проблемы является принции «методологического индивидуализма», который признает реально действующими участниками социального процесса не группы или организации, а индивидов. Согласно этому принципу коллективные общности (например, фирмы или государство) не обладают самостоятельным существованием, отдельным от составляющих их членов, и поэтому должны объясняться с точки зрения целенаправленного поведения индивидов [8]. К основным субъектам образовательного процесса традиционно относятся обучающиеся: студенты, аспиранты, педагогические работники, административные работники, коллегиальные органы управления, общественные объединения и формирования университета. В настоящее время актуализировалось участие новых субъектов: родителей, работодателей, органов местного самоуправления и органов регионального управления, с которыми также важно поддерживать диалогические взаимоотношения. Является очевидным, что у каждого из перечисленных субъектов интересы выстраиваются по шкале: от профессиональных, экономических, управленческих, коллективных до социальных, индивидуальных, карьерных. Если использовать личностный подход к характеристике векторов взаимодействия основных субъектов образовательного процесса, то можно обнаружить разнообразие их интересов, мотивов, ценностей, потребностей, которые образуют разнонаправленную сложную ткань взаимодействий, объединенных в социальное пространство с соответствующими координатами, стратификационная суть которого (дифференциация и иерархизация) описана в трудах П. Сорокина [9]. Чтобы управление было эффективным, надо определить способы диагностики наиболее существенных взаимодействий субъектов образования, найти с помощью диалога действенные технологии и инструменты воздействия на их социальную и академическую активность.
По-прежнему главными субъектами образования остаются студенты и преподаватели. Их коммуникативное взаимодействие регулируется институциональными формальными и неформальными правилами: законами, кодексами, нормами, традициями, обычаями, академическими ритуалами, способами контроля, системой поощрений и санкций. Рыночные отношения повлияли на особенности взаимодействия между ними, а поэтому и на формы диалога, но неизменным остается очевидный факт, что в процессе диалога происходит обмен социальной информацией, ценностями, эмоциями между его участниками, трансляция социального опыта.

Студенчество как целевая группа и ресурсный социокультурный, интеллектуальный, экономический потенциал общества является объектом воздействия, с одной стороны, новой социальной реальности, с другой стороны, идей, ценностей и установок, транслируемых в стенах учебного заведения. Часто подобные воздействия производят противоположный эффект, что может быть выявлено в процессе диалога. Ю.А. Зубок считает, что студенчество, как наиболее сплоченная группа современной молодежи, находясь в состоянии неопределенности и рисков, конструирует свои модели поведения, когда молодые люди как бы приспосабливают изменяющуюся действительность для реализации своих целей и потребностей [3]. Обращаясь к идеям П. Штомпки о том, что в процессе социальных изменений трансформируются интересы и идеи [11], важно в процессе социального диалога выявить направленность и динамику интересов и ценностей студенческой молодежи. Практика показывает, что преимущественно для нее характерен индивидуализм и ориентация на личные интересы в построении профессиональной карьеры. Объяснение обнаруженной тенденции дано Ю.А. Зубок, которая выделила гибридный тип интересов и ментальных особенностей молодежи, характерных для традиционной и новой рыночной культуры [4]. При аргументации своей позиции она обращается к концепции П. Сорокина [9], позволяющей проследить общее и особенное в динамике культуры, присущей конкретному обществу, оценить степень воспроизводства смысловых образцов культуры в молодежной среде. В ментальности тради- 
ционной, идеациональной культуры доминируют преимущественно духовные цели и потребности, соответственно, в чувственной рыночной акцент делается на удовлетворение физических потребностей и приспособление для этих целей внешнего мира и его ресурсов. Кроме различий в поведении студентов, обусловленных социокультурными регуляторами, в студенческой среде происходит углубление социальной дифференциации между участниками образовательного процесса, обусловленное уровнем материального благополучия и достатка родителей, доступом к культурным и спортивным благам, наличием платных образовательных услуг и т.д. Все эти черты могут отражаться на содержании, достоверности мнений и оценок в процессе диалога администрации вуза и студентов. Требует осмысления с точки зрения управленческих технологий изменяющаяся модель взаимодействия между преподавателем и обучающимся (поставщик знания - потребитель знания), направленная на приобретение компетенций, формирование определенной поведенческой модели, отвечающей конкретным, практическим экономическим задачам, а не нацеленной на развитие личности специалиста, готовой успешно интегрироваться в новую социальную реальность и быть хранителем культурных традиций.

Использование социального диалога администрацией вузов во взаимодействии со студентами может стать ресурсом актуализации важных параметров оценки роли научно-педагогических работников в повышении эффективности управления образовательным процессом на основе диагностики уровня доверия к ним и привлекательности в студенческой среде. Сторонники социально-психологических подходов считают, что доверие к преподавателю складывается из компетентности: наличие определенного профессионального опыта, знание и использование специальной лексики и научной терминологии; искренности - когда он говорит честно, не собирается убеждать оппонентов в правильности своей точки зрения и подтверждает готовность выслушать другое мнение; надежности - когда его высказывания не противоречат друг другу, а сделанные им прогнозы уже сбывались ранее.

Важная роль в социальном диалоге отводится заведующим кафедрами, деканам факультетов, работникам администрации вузов, имеющим формализованные статусные позиции, наделенным управленческими полномочиями и владеющим инструментами вознаграждения и принуждения. Для руководителей разных уровней важно использовать диалог для убеждения всех участников образовательного процесса продуктивно действовать для достижения общих целей. Умение быть участником паритетного диалога также во многом определяется личностными чертами субъектов образования.

Социальный диалог и принципы управления университетом. Известно, что эффективное управление предполагает устойчивое функционирование обратной связи между субъектами и объектами, которая может быть безоценочной, положительной или негативной. Управление университетом опирается на следующие основные принципы управления в системе образования, изложенные в Ф3 «Об образовании в Российской Федерации»: государственная регламентация, стратегическое планирование, информационное и методическое обеспечение, независимая оценка качества, общественно-профессиональная аккредитация, проведение мониторинга в системе образования [13]. Их развернутая характеристика дана в статье 26 «Управление образовательной организацией», в которой подчеркивается важность сочетания принципов единоначалия и коллегиальности, а также нормативное требование учета мнения обучающихся, законных представителей несовершенных обучающихся и педагогических работников [13]. С реализацией данной нормативноправовой установки связано использование потенциала социального диалога в управлении образовательным учреждением, который обеспечивает возможность внутривузовских административных структур «держать постоянно руку на пульсе состояния общественного мнения», поддерживать в актуальном состоянии обратную связь для своевременного принятия управленческих воздействий с целью устранения острых социальных вопросов, противоречий и разногласий в образовательной системе. Уровень современных информационных технологий позволяет реализовать непосредственные и опосредованные формы диалога. 
В настоящее время сложилась традиционная система взаимодействий студентов, профессорско-преподавательского состава, администрации, которая отличается преимущественно непосредственным характером общения - собрания, заседания ученых советов, встречи, личный прием и т.д., при этом форма осуществления чаще всего монологична. Дистанционный режим актуализировал опосредованное взаимодействие, когда эмоциональная составляющая заменяется формальной, когнитивной, цифровой. Сочетание традиционных и новых форм взаимодействия в социальном пространстве создает обстановку социальной турбулентности, которая как раз и актуализирует роль диалога: нужен ли он, какие приобретает формы, или управление современным вузом должно опираться только на формальные нормы и правила?

Заключение. Таким образом, институциональные изменения в системе высшего образования актуализировали социальную активность всех субъектов образовательного процесса как полноправных участников управленческих технологий. Позитивным потенциалом для выработки своевременных управленческих решений является социальный диалог между всеми субъектами образования на принципах открытости, равенства, паритета. Новая социальная реальность изменила статусно-ролевые отношения между преподавателями и студентами, вместо традиционных «учитель - ученик», расширяются другие: «поставщик знания - потребитель знания», которые сдвигают акценты в целях образования с развития личности на формирование профессионала. Социальный диалог в управлении университетом содержит в себе потенциал социализации студенческого сообщества, позитивный ресурс социальной консолидации профессорско-преподавательского состава, административно-управленческих структур, родителей и работодателей.

\section{Литература}

1. Вебер М. Основные социологические понятия // Западно-европейская социология XIX - начала XX веков. - М., 1996. C. $460-466$.
2. Емельянов Ю. Н. Обучение паритетному диалогу. РИО Ленинградского университета. - 1991 г. - 106 с. - С. 3.

3. Зубок Ю.А., Чупров В.И. Самоорганизация в проявлениях молодежного экстремизма // Социологические исследования, 2009. - №1. - С. 79.

4. Зубок Ю.А., Чупров В.И. Жизнедеятельность молодежи в культурном пространстве изменяющейся реальности: теоретические подходы к исследованию // В сборнике: Культурное пространство молодежи: смыслы и практики. Материалы Всероссийской научно-практической конференции. Под общей редакцией Т.К. Ростовской. 2019. - C. 9-18.

5. Курбатов В.И. Социальный диалог: концептуальный анализ // Гуманитарий Юга России. - 2014. - С. 103-112.

6. Новая социальная реальность: системообразующие факторы, безопасность и перспективы развития. Россия в техносоциальном пространстве (Коллективная монография). М.; СПб.: Нестор-История, 2020. - 208 с.

7. Норт Д. Институты, институциональные изменения и функционирование экономики. - М., 1997.

8. Сорокин П. А. Человек. Цивилизация. Общество / Общ. ред., сост. и предисл. Ю. Согомонов: Пер. с англ. - М.: Политиздат, 1992.

9. Сорокин П.А. Социальная и культурная динамика: исследование изменений в больших системах искусства, истины, этики, права и общественных отношений. СПб.: РХГИ, 2000.

10. Социальный диалог: повседневный дискурс и социальные практики: монография; Южный федеральный университет. Ростов-на-Дону: Издательство Южного федерального университета, 2012. - 236 с.

11. Штомпка П. Социология. Анализ современного общества: Пер. с польск. С.М. Червонной. - М.: Логос, 2005. - 664 с.

12. Федеральный закон «Об образовании в Российской Федерации». - М.: Издательство «Омега-Л», 2014. — 136 с.

\section{References}

1. Veber M. Osnovnye sociologicheskie ponjatija [Basic sociological concepts] // 
Zapadno-evropejskaja sociologija XIX-nachala $\mathrm{XX}$ vekov [Western European sociology of the XIX - early XX centuries]. - Moscow, 1996. - Pp. 460-466.

2. Emel'janov $J u$. N. Obuchenie paritetnomu dialogu [Training for a parity dialogue]. RIO Leningradskogo universiteta. - 1991 g. 106 p. - P. 3.

3.ZubokJu.A., Chuprov V.I.Samoorganizacija $\mathrm{v}$ projavlenijah molodezhnogo jekstremizma [Self-Organization in the manifestations of youth extremism] // Sociologicheskie issledovanija [Sociological research], 2009. — №1. — P. 79.

4. Zubok Ju. A., Chuprov V.I. Zhiznedeja tel'nost' molodezhi $\mathrm{v}$ kul'turnom prostranstve izmenjajushhejsja real'nosti: teoreticheskie podhody $\mathrm{k}$ issledovaniju [Youth life Activity in the cultural space of changing reality: theoretical approaches to research] // V sbornike: Kul'turnoe prostranstvo molodezhi: smysly i praktiki. Materialy Vserossijskoj nauchno-prakticheskoj konferencii [In the collection: cultural space of youth: meanings and practices. Materials of the all-Russian scientific and practical conference]. In T.K. Rostovskaya (eds.). — 2019. - Pp. 9-18.

5. Kurbatov V.I. Social'nyj dialog: konceptual'nyj analiz [Social dialogue: conceptual analysis] // Gumanitarij Juga Rossii [Humanities of the South of Russia]. - 2014. Pp. 103-112.

6. Novaja social'naja real'nost': sistemoobrazujushhie faktory, bezopasnost' i perspektivy razvitija. Rossija v tehnosocial'nom prostranstve (Kollektivnaja monografija) [New soci- al reality: system-forming factors, security and development prospects. Russia in the technosocial space (Collective monograph)]. Moscow; Saint-Petersburg: Nestor-Istorija, 2020. - $208 \mathrm{p}$.

7. Nort $D$. Instituty, institucional'nye izmenenija i funkcionirovanie jekonomiki [Institutes, institutional changes and functioning of the economy]. - Moscow, 1997.

8. Sorokin P.A. Chelovek. Civilizacija. Obshestvo [Man. Civilization. Society] / In Ju. Sogomonov (eds.). — Moscow: Politizdat, 1992.

9. Sorokin P.A. Social'naja i kul'turnaja dinamika: issledovanie izmenenij $\mathrm{v}$ bol'shih sistemah iskusstva, istiny, jetiki, prava i obshhestvennyh otnoshenij [Social and cultural dynamics: research of changes in large systems of art, truth, ethics, law and public relations]. Saint-Petersburg: RHGI, 2000.

10. Social'nyj dialog: povsednevnyj diskurs i social'nye praktiki: monografija; Juzhnyj federal'nyj universitet [Social dialogue: everyday discourse and social practices: monograph; southern Federal University]. - Rostov-on-Don: Izdatel'stvo Juzhnogo federal'nogo universiteta, 2012. - $236 \mathrm{p}$.

11. Shtompka P. Sociologija. Analiz sovremennogo obshhestva [Sotsiologiya. Analysis of modern society]. - Moscow: Logos, 2005. $664 \mathrm{p}$.

12. Federal'nyj zakon «Ob obrazovanii v Rossijskoj Federacii» [Federal law «On education in the Russian Federation»]. - Moscow: Izdatel'stvo «Omega-L», 2014. - 136 p. 


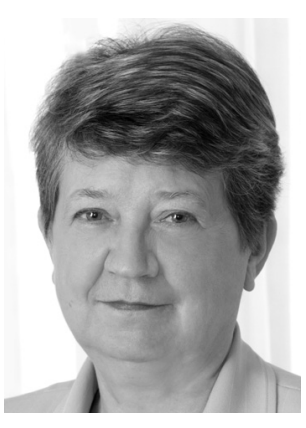

Щербакова Лидия Ильинична - профессор, доктор социологических наук, профессор кафедры «Социальные и гуманитарные науки» Южно-Российского государственного политехнического университета (НПИ) имени М.И. Платова.

Shcherbakova Lidiya Il'inichna - Professor, Doctor of Sociological Sciences, Professor, Department of Social and Humanitarian Sciences, Platov South-Russian State Polytechnic University (NPI).

346421, г. Новочеркасск, пр. Баклановский, 97, кв. 98 97 Baklanovsky av., app. 98, 346421, Novocherkassk, Russia

E-mail: lidia-npi@mail.ru 